\title{
A content analysis of ideal, ought, and feared selves in patients with chronic low back pain
}

\author{
Hanne P. Kindermans ${ }^{a, *}$, Marielle E. Goossens ${ }^{a}$, Jeffrey Roelofs ${ }^{a}$, Ivan P. Huijnen ${ }^{b}$, \\ Jeanine A. Verbunt ${ }^{\mathrm{b}}$, Stephen Morley ${ }^{\mathrm{c}}$, Johan W. Vlaeyen ${ }^{\mathrm{a}, \mathrm{d}}$ \\ ${ }^{a}$ Department of Clinical Psychological Sciences, Maastricht University, Maastricht, The Netherlands \\ ${ }^{\mathrm{b}}$ Department of Rehabilitation Medicine, Maastricht University, Maastricht, The Netherlands \\ ${ }^{\mathrm{c}}$ Institute of Health Sciences, University of Leeds, Leeds, United Kingdom \\ ${ }^{\mathrm{d}}$ Research Center Health Psychology, Department of Psychology, University of Leuven, Leuven, Belgium
}

\section{A R T I C L E I N F O}

\section{Article history:}

Received 20 February 2009

Received in revised form 28 September

2009

Accepted 19 October 2009

Available online 1 December 2009

\section{Keywords:}

Chronic low back pain

Self-discrepancy

Disability

Identity

Content analyses

\begin{abstract}
A B S T R A C T
Patients with chronic pain are not only faced with disabilities but are also challenged to maintain a valued sense of self. This sense of self is in part determined by the extent to which patients can accomplish their identity-related goals. The present study explores the content of three domains of the self, namely the ideal, ought and feared self and examines how the content relates to disability and depression.

The ideal, ought and feared attributes of 80 chronic low back pain patients were analyzed and categorized in eight general goal-domains: interpersonal attributes, personal abilities, physical, emotional and psychological well-being, close interpersonal relationships, self-expression abilities, achievement-related attributes, physical appearance, and religion. Results showed that most of the attributes that patients generated involved interpersonal attributes. Comparisons between the self-guides revealed that ideal attributes were more intrapersonally focused while ought and feared attributes were interpersonally focused. The content appeared to be related to disability but not to depression. More specifically, the more disabled patients were, the more they listed well-being related attributes as part of their ought self. None of the other goal-domains was related to disability or depression.

The present study provides additional insight into the goals of patients with chronic pain at the level of identity and has shown that these are, at least in part, related to the level of functional disability. These results might be useful for future studies incorporating the role of identity in chronic pain, such as psychological interventions.
\end{abstract}

( 2009 European Federation of International Association for the Study of Pain Chapters. Published by Elsevier Ltd. All rights reserved.

\section{Introduction}

The self and identity can be seen as an individuals' knowledge and understanding of his or her self, and has received increased attention in the field of chronic pain. Several authors put forward that chronic pain is associated with loss of desired social roles or attributes, and hence, has detrimental effects on the sense of self (e.g., Harris et al., 2003; Morley and Eccleston, 2004; Smith and Osborn, 2007). Based on Higgins' Self-Discrepancy Theory (SDT; Higgins, 1987), the study of the self in chronic pain has focused on three self-guides (i.e. self-directive standards), that refer to regulating the actual self based on the experienced discrepancies between the actual self and the ideal self-guide (reflecting aspirations), the ought self-guide (reflecting duties), and the feared self-guide (reflecting fears). In chronic pain populations, this line of

\footnotetext{
* Corresponding author. Tel.: +31 43 3872487; fax: +31 433884155 .

E-mail address: H.Kindermans@dmkep.unimaas.nl (H.P. Kindermans).
}

research not only has confirmed SDT's predicted relationships between discrepancy and psychological distress, it also extended these findings with important relationships between discrepancies, pain experience, and disability (Morley et al., 2005; Sutherland and Morley, 2008; Waters et al., 2004) ${ }^{1}$.

However, none of these studies has shed light on the content of self-guides, while it is known from research in other domains that this might be related to health status. For example, a content analyses of the feared identity of patients with obsessive compulsive behaviour illustrated that this behaviour might be a strategy to prevent their feared self, characterized by a 'dangerous me' theme (Ferrier and Brewin, 2005). Moreover, the content of the selfguides might serve as a lead for treatment and with the growing interest in identity-related motivational treatments for chronic pain patients (Van Damme et al., 2008), there is a need for more

\footnotetext{
1 Morley et al. (2005) and Sutherland and Morley (2008) used the hoped-for self but this has been shown to be saturated with attributes of the ideal self.
} 
insight into patients' identity-related goals. A first attempt to explore the content of self-guides in chronic pain patients revealed that the feared self embodies pain and physical health-related attributes. Yet, these findings rely on merely providing examples of attributes patients feared (Morley and Eccleston, 2004). Therefore, a systematic investigation is needed to draw firm conclusions on the content of self-guides in chronic pain patients.

The first aim of the present study was to provide a content analysis of selves in patients with chronic low back pain. The ideal, ought, and feared self-guides were examined by means of a categorization structure for 30 goal-domains provided by Chulef et al. (2001). In the current study, this categorization was used to identify which of the 30 categories were most frequent and how this differs between self-guides. Based on the findings of Morley and Eccleston (2004), the self-guides were hypothesized to contain pain or health-related selves. Second, we explored whether the content of the selves was related to the level of disability. We hypothesized that higher levels of disability would be related to a higher number of pain and health-related selves. Furthermore, the role of depression was explored, as in previous studies the magnitude of self-discrepancies in pain patients has shown to be associated with depression (e.g., Waters et al., 2004).

\section{Method}

\subsection{Participants}

The present study was part of an ongoing longitudinal cohort study from which baseline data were used. Participants were 80 patients (39 women and 41 men) with non-specific chronic low back pain who were recruited from departments of rehabilitation medicine in hospitals and a rehabilitation center in the South of The Netherlands and through advertisements placed in local newspapers. There were no significant differences on socio-demographics or disability or depression scores between participants from different locations, except for age differences, which were controlled for in the analyses. Ages ranged from 22 to 65 years with a mean of 47.8 years. Mean average pain duration was 11.2 years (range 5 months to 44 years). Approximately half of all participants were still employed for more then $30 \mathrm{~h}$ per week (33.8\%) or less then $30 \mathrm{~h}$ per week (17.6\%). $21.6 \%$ were recipients of disablement insurance benefits. All others were unemployed. With regard to education level, most of the participants completed lower secondary professional education (58.9\%), 30.1\% higher general secondary education $(30.1 \%)$, and a minority achieved vocational training or higher education (11\%).

\subsection{Measures}

\subsubsection{Self-guides}

Hardin's Selves Questionnaire (HSQ; Hardin and Leong, 2005) was used to identify significant attributes in three domains of the self: the ideal self, the ought self, and the undesired self. Consistent with Carver and colleagues (1999), the undesired self was reformulated in terms of the feared self. Based on earlier experiences, the HSQ was administered in the form of a semi-structured interview to facilitate better understanding of the questions. Patients were asked to generate 10 attributes for the ideal self-guide ("Which attributes would you ideally like to possess?"), the ought self-guide ("Which attributes do you think you should possess?") and the feared self-guide ("Which attributes do you fear to possess?"). Of these 10 attributes, five attributes were generated from their own perspective and five from the perspective of a significant other (e.g. spouse). This resulted in a total of thirty attributes per patient. Patients were first encouraged to come up with attributes themselves but if they experienced difficulties they were provided with a list of attributes (e.g. helpful, lazy) to complete the questionnaire. This combination of idiographic and nomothetic questionnaire methods ensures salience of attributes and feasibility of completing the questionnaire. The HSQ has found to be a reliable and valid instrument of assessing self-discrepancies (Hardin and Leong, 2005).

\subsubsection{Disability}

Disability was measured with the Roland Disability Questionnaire (RDQ; Roland and Morris, 1983). The RDQ is a self-report questionnaire consisting of 24 items reflecting the level of impairment in the performance of daily activities, that are given a score of 1 (my low back pain interferes with this activity) or 0 (no interference). Total scores range from 0 (not disabled) to 24 (seriously disabled). The reliability and validity of the Dutch version of the RDQ have been supported (Brouwer et al., 2004).

\subsubsection{Depression}

Depression was measured by the Beck Depression Inventory II (BDI-II; Beck et al., 1996). The BDI-II is a self-report questionnaire which measures depressive symptoms in 21 items. For each item, several possible responses are listed with scores ranging from 0 to 3 . Total scores are obtained by adding the responses on the 21 items, leaving a range from 0 to 63, in which higher scores reflect more depressive symptomatology. The BDI-II has good validity and reliability scores (Beck et al., 1996).

\subsubsection{Pain intensity}

Pain intensity was measured with three $100 \mathrm{~mm}$ Visual Analogue Scales (VAS; Price et al., 1983). Patients were asked to rate their actual pain (at that moment) and their worst and best pain level of the past week on three separate VAS-scales. A general pain intensity composite score was calculated by calculating the mean of the aforementioned three VAS-scales. This composite score was used in further analyses.

\subsection{Procedure}

Patients were either referred to the study by their consultant in rehabilitation medicine or contacted the researchers themselves as a result of the advertisement about the study in local newspapers. Patients who responded to the advertisement were screened by a consultant in rehabilitation medicine before participating in the study. After the informed consent procedure, patients were given the choice to have the HSQ-interview at the university or by telephone. Subsequently, patients could either complete the questionnaires on paper or on-line through the internet. All patients $(N=80)$ completed the interview but seven did not fill in the questionnaires. The study protocol was approved by the Medical Ethical Committee of the Maastricht University Medical Center (The Netherlands).

\subsection{Data analysis}

\subsubsection{Content analysis of the HSQ}

Responses to the HSQ were categorized as follows using the 30 categories reported by Chulef et al. (2001) in their study of general human goals (see Table 1; Chulef et al., 2001). Two independent raters with a clinical psychology background, blind to the objectives of the study, were provided with a list of all unique attributes elicited by the participants when filling in the HSQ. The attributes were put in alphabetical order. The raters were also given a list of the 30 categories of general goals from Chulef et al. (2001). Each category was accompanied by a definition and by the sub-categories going together with that specific category (see Table 1 ). The 
Table 1

The original categories organized according the new categories with examples of attributes of the ideal, ought, and feared self.

\begin{tabular}{|c|c|c|c|c|}
\hline \multirow[t]{2}{*}{ New category } & \multirow[t]{2}{*}{ Original categories } & \multicolumn{3}{|l|}{ Self aspects } \\
\hline & & Ideal self & Ought self & Feared self \\
\hline $\begin{array}{c}\text { Interpersonal } \\
\text { attributes }\end{array}$ & $\begin{array}{l}\text { 'Belonging, social recognition and approval' 'Friendship' 'Receiving from others' } \\
\text { 'Defence versus rejection' 'Positive social qualities' 'Teaching and helping others' } \\
\text { 'Leadership' 'Social awareness' 'Ethics and idealism' 'Flexibility, openness and } \\
\text { excitement' }\end{array}$ & $\begin{array}{l}\text { 'Honest' } \\
\text { 'Patient' }\end{array}$ & 'Friendly' 'Helpful' & 'Greedy' 'Selfish' \\
\hline Personal abilities & 'Order' 'Achievement' 'Self-sufficiency and determination' & $\begin{array}{l}\text { 'Ambitious' } \\
\text { 'Go-getter' }\end{array}$ & $\begin{array}{l}\text { 'Hard working' } \\
\text { 'Independent' }\end{array}$ & 'Lazy’ ‘Slovenly’ \\
\hline $\begin{array}{l}\text { Physical, emotional } \\
\text { and psychological } \\
\text { well-being }\end{array}$ & $\begin{array}{l}\text { 'Physical health' 'Amusement' 'Psychological well-being' 'Stability and safety' } \\
\text { 'Higher meaning' 'Personal growth' }\end{array}$ & $\begin{array}{l}\text { 'Healthy' } \\
\text { 'Without pain' }\end{array}$ & $\begin{array}{l}\text { 'Accepting of } \\
\text { complaints' } \\
\text { 'Energetic' }\end{array}$ & $\begin{array}{l}\text { 'Less active' } \\
\text { 'Unhealthy' }\end{array}$ \\
\hline $\begin{array}{l}\text { Close interpersonal } \\
\text { relationships }\end{array}$ & 'Sex and romance' 'Marriage' 'Family' & $\begin{array}{l}\text { 'Loyal husband' } \\
\text { 'Good } \\
\text { housewive' }\end{array}$ & $\begin{array}{l}\text { 'Good father' } \\
\text { 'Being there for the } \\
\text { family' }\end{array}$ & $\begin{array}{l}\text { 'Unfaithful' } \\
\text { 'Strict with } \\
\text { children' }\end{array}$ \\
\hline $\begin{array}{l}\text { Self-expression } \\
\text { abilities }\end{array}$ & 'Freedom' 'Aesthetics' 'Creativity' & 'Artistic' 'Free' & $\begin{array}{l}\text { 'Inventive' } \\
\text { 'Creative' }\end{array}$ & $\begin{array}{l}\text { 'No longer able } \\
\text { to take care of } \\
\text { self' }\end{array}$ \\
\hline $\begin{array}{l}\text { Achievement-related } \\
\text { attributes }\end{array}$ & 'Career' 'Intellect and education' 'Finances' & $\begin{array}{l}\text { 'Intelligent' } \\
\text { 'Inquisitive' }\end{array}$ & $\begin{array}{l}\text { 'Analytical' } \\
\text { 'Employed' }\end{array}$ & $\begin{array}{l}\text { 'Materialistic' } \\
\text { 'Too generous' }\end{array}$ \\
\hline Physical appearance & 'Physical appearance' & $\begin{array}{l}\text { 'Attractive' } \\
\text { 'Slim' }\end{array}$ & $\begin{array}{l}\text { 'Decent' 'Well- } \\
\text { cared-for' }\end{array}$ & $\begin{array}{l}\text { 'Uncared-for } \\
\text { look' }\end{array}$ \\
\hline Religion & 'Religion' & 'Religious' & ‘Religious’ & 'Unchristian’ \\
\hline
\end{tabular}

two raters were requested to provide each single attribute with a code ranging from 1 to 30 , reflecting one of the 30 categories from Chulef et al. (2001). For the feared attributes, having a negative valence, the raters evaluated the attribute based on its reverse. For example, the feared self 'unhealthy' is the reverse of 'healthy', and belongs to the category 'Physical Health'.

\subsection{Statistical analysis}

Data were analyzed using the Statistical Package for Social Sciences (SPSS 13.0). After completion of the categorization of the content of the self-guides, the number of times a patient generated an attribute of that specific category within a specific self-guide was calculated. This was done for each self-guide from both perspectives separately (ought own - ought other, ideal own - ideal other, feared own - feared other).

Prior to analysis, we checked whether the measurement scores were normally distributed. For some variables, skewness and kurtosis deviated from the acceptable range of -1 to +1 . For these variables non-parametric analyses were performed. To investigate differences in the frequency of content categories across selfguides, Friedman tests and post hoc Wilcoxon signed rank tests were conducted. Furthermore, the relationships between the content categories and disability and depression were determined by partial Pearson correlations or non-parametric partial Kendall's tau correlations, dependent on the distribution of the variables tested. Gender, age, pain duration, and pain intensity were partialled out in these analyses. To prevent type I errors due to multiple testing, a Bonferroni correction was applied to Friedman tests and Wilxocon signed rank tests, resulting in an alpha of .008 for Friedman tests and.004 for Wilcoxon signed rank tests. For the partial correlations coefficients, alpha was set to .01 .

\section{Results}

\subsection{General descriptive information}

Before addressing the main results, descriptive information from the questionnaires is presented. Mean pain intensity as assessed on a $100 \mathrm{~mm}$ visual analogue scale was $50.5(\mathrm{SD}=17.3)$. The mean disability score $(\mathrm{RDQ})$ was $11.7(\mathrm{SD}=4.7)$ and the mean depression score (BDI-II) was $13.7(\mathrm{SD}=11.2)$.

\subsection{Categorization of the content of the self-guides}

In total, patients listed 905 unique attributes in the HSQ for the ideal, ought, and feared selves from both perspectives. Two independent raters categorized these attributes into 30 categories of general human goals. The initial inter-rater reliability was low (Cohen's Kappa $=.38, p<.001$ ), which was not surprising given the large number of attributes and categories. In deciding how to deal with this finding, an expert meeting involving all authors of this paper was organized, during which it was decided to merge categories based on the number of attributes the raters systematically disagreed on. Categories with similar content but rated differently and categories that were seldomly selected by both raters were lumped together. Additionally, the cluster solution as presented by Chulef and colleagues (2001) was taken as a general lead. A third independent rater resolved disagreements by assigning the attribute to one of the two categories the initial raters disagreed on. This process resulted in a reduction of the 30 categories to 8 categories with a satisfactory Cohen's Kappa of $.62(p<.001)$ and an overall simple agreement coefficient of $72.4 \%$ (905-250/905). Table 1 presents the 8 categories as well as some examples for the ideal, ought and feared self within each of these categories.

\subsection{The content of the Ideal, ought and feared selves}

Fig. 1 displays frequency data of the categories for each selfguide. In the absence of any significant differences in content between own and other perspectives, the frequencies of the own and the other perspective were summed for each self-guide. Consequently, the bars in the figure represent the frequencies of the self-guides regardless of the perspective.

The majority of the attributes that patients generated appear to relate to their interpersonal life, physical, emotional and psychological well-being and to personal abilities. The pattern of results was largely comparable across the three self-guides. Compared to attributes relating to the broad interpersonal domain, patients mentioned fewer attributes related to the close interpersonal domain (within the family or romantic relationships). The number of times that self-expression abilities (e.g. creative) or religion-related attributes, were mentioned is negligible. For this reason, these categories were not subjected to further analyses. 
While a same trend in the prevalence of content categories can be observed for the ideal, ought, and feared self, there are differences in content between the self-guides. Friedman tests showed differences between the ideal, ought, and feared self for the following categories 'Interpersonal attributes' $\left(\chi^{2}(2)=23.39, p<.001\right)$, 'Physical, emotional and mental well-being' $\left(\chi^{2}(2)=10.16\right.$, $p<.008)$, 'Close interpersonal relationships' $\left(\chi^{2}(2)=12.67, p=\right.$ $.001)$ and 'Physical appearance' $\left(\chi^{2}(2)=11.51, p<.008\right)$. Post hoc Wilcoxon signed rank tests were used to identify these differences. Analyses showed that the ought self was characterized by more 'Interpersonal attributes' (as compared to the ideal self; $z=4.64$, $p<.001$ and the feared self; $z=4.14, p<.001$ ). Accordingly, an interpersonal attribute such as 'being helpful' is something patients often impose on themselves or feel imposed upon them by others (also see Table 1). On the other hand, patient's ideal self was characterized by more attributes related to 'Physical, emotional and mental well-being' as compared to the ought self, $(z=4.01, p<.001)$. For example, 'being healthy' is something patients would ideally like to be but do not necessarily (or to a lesser degree) feel compelled to be. Attributes related to 'Close interpersonal relationships' were mentioned more times in the feared self in contrast to the ideal self, $(z=3.23, p=.001)$. As an illustration; being a bad parent is something patients fear more as compared to ideally wanting to be a good parent.

\subsection{The relation between disability and depression, and the content of the self-guides}

We hypothesized that disability and depressive symptoms would be associated with the content of the self-guides in the sense that patients with higher levels of disability and/or depression would yield more physical-related attributes. As a consequence of the merging of the categories this hypothesis could not be tested solely for physical-related attributes but was tested in the larger context of 'Physical, emotional and psychological wellbeing'. Table 2 presents the results of the partial correlational analyses between the content categories and, disability and depression, controlling for gender, age, pain duration, and pain intensity. First, we aggregated the number of times a particular category was mentioned per self-guide. In other words, the scores reflect the number of times a patient mentioned a particular category regardless of the self-guide. Both categories 'physical, emotional and psychological well-being' and 'physical appearance' seemed to be related to disability but only at $p<0.05$. As we expected that the more disabled patients are, the more they generate attributes related to physical, emotional or psychological well-being as part of their ideal, ought or feared self, we further explored this relationship per self-guide. Partial correlations were performed between disability and the number of times this category was mentioned for each self-guide, controlling for gender, age, pain duration, and pain intensity. Disability was related exclusively to the number of times patients felt they ought to possess attributes concerning their well-being $(\tau=.23 ; p=.002)$ but not to the number of times they ideally would like to $(r=.16 ; p=.23)$ or fear to possess $(r=.14 ; p=.28)$ these attributes.

With regard to the relationship between the content of the selfguides and depression, no significant relations were found. The number of attributes patients listed within certain domains was not related to their level of depression.

\section{Discussion}

The present study sought to shed light on the content of the ideal, ought, and feared self-guides of patients with chronic low back pain and the relationships between the content and disability and depression. The results can be summarized as follows. First, the attributes pain patients generate could be categorized using eight high level categories. Second, the hypothesized pain and health-related attributes were indeed present, and were incorporated in the broader category 'Psychological, emotional and physical wellbeing'. These attributes were most often mentioned within the ideal self-guide. Social and interpersonal attributes were also incorporated within the ought self-guide. Finally, patients who reported higher levels of disability also mentioned more well-being related attributes as part of their ought self-guide. Unexpectedly, depression was not related to the content of the self-guides.

The ideal, ought, and feared attributes that patients listed from both perspectives, could all be categorized into eight categories. Initially, the thirty categories structure from Chulef et al. (2001) was used but this resulted in a low agreement between raters

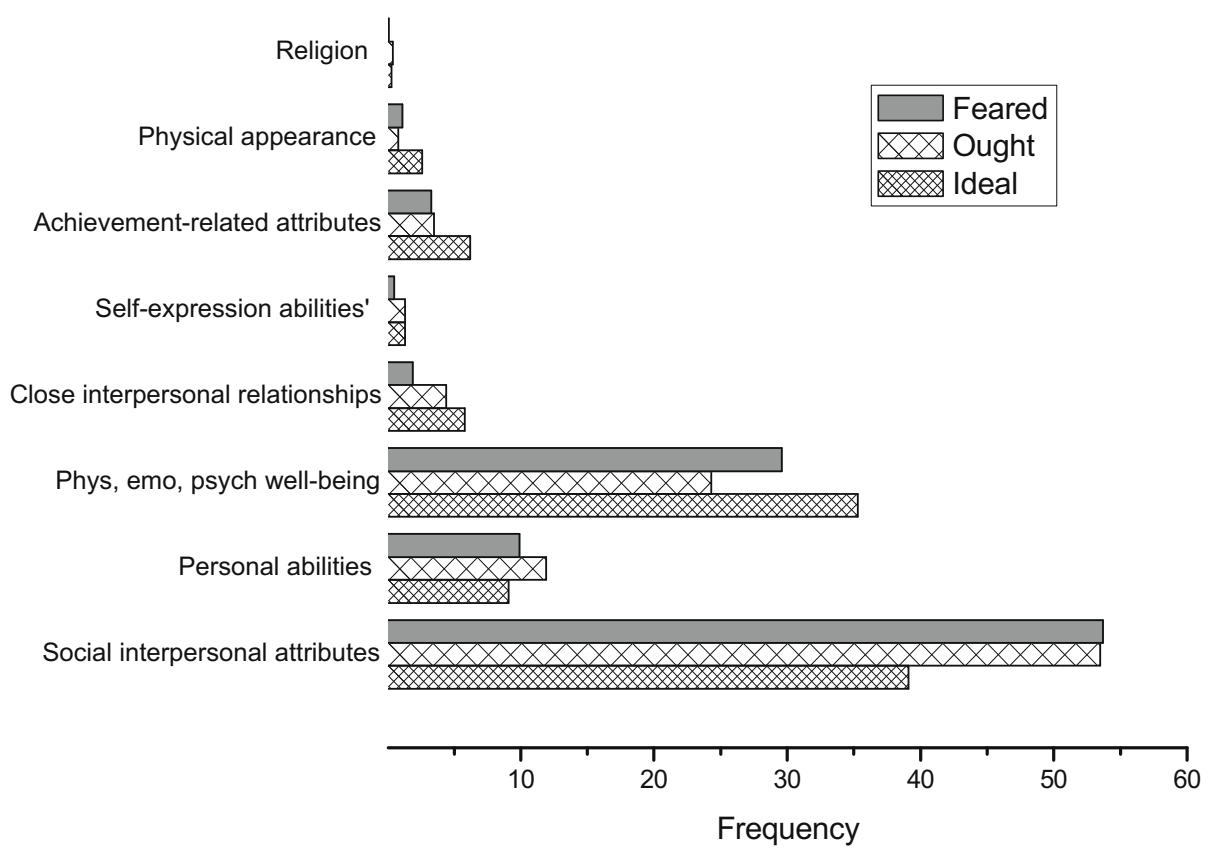

Fig. 1. Frequencies of categories in the ideal, ought, and feared self-guides. 
Table 2

Partial correlations between the content categories and disability and depression controlling for gender, age, pain duration, and pain intensity.

\begin{tabular}{lll}
\hline & Disability & Depression \\
\hline Interpersonal attributes $^{\mathrm{a}}$ & -.06 & .01 \\
Personal abilities $^{\mathrm{a}}$ & -.01 & -.17 \\
Physical, emotional, and psychological well-being $^{\mathrm{a}}$ & $.28^{*}$ & .22 \\
Close interpersonal relationships $^{\mathrm{b}}$ & -.01 & -.05 \\
Achievement-related attributes $^{\mathrm{b}}$ & -.11 & .03 \\
Physical appearance $^{\mathrm{b}}$ & $-.17^{*}$ & -.12 \\
\hline
\end{tabular}

a Pearson partial correlations.

b Kendall's tau partial correlations.

$p<.05$.

due to the large number of categories in combination with the large number of attributes. A process of merging the thirty categories resulted in the final eight categories. Despite the need for a replication in another sample of patients, the eight categories did provide informational value and was used to answer the research questions.

For patients with chronic pain, not only the loss of physical well-being is a burden but also the (threat of) loss of their social roles (Harris et al., 2003; Morley and Eccleston, 2004; Ranjan, 2004). The results from the present study indicate that most attributes can be categorized as 'Interpersonal attributes', which illustrates the importance of the societal role to patients with chronic pain. That is, the person they want to, feel compelled to, or fear to be in their social environment, in relation to others. In addition, attributes related to 'Psychological, emotional, and physical wellbeing' represented the second largest category of all attributes. A tentative conclusion that might be drawn from these findings, is that for patients with chronic low back pain, the challenges they face involving their social role functioning are at least as important for their sense of self as their health condition. In addition, results from the comparisons between the content of self-guides provide insight into the role of different connotations with respect to self-goals. The fact that there were indeed differences in content between the self-guides already suggest that it is worthwhile studying all three types of self-guides. With respect to the results, we might conclude that the focus of the ideal self is in the intrapersonal domain, while the ought and feared self seem more focused at the interpersonal domain. These findings may be of interest in light of the emotional and self-regulatory consequences of discrepancies between the actual self and specific self-guides. As mentioned before, the content of the self-guides might be related to the demonstrated behaviour (Ferrier and Brewin, 2005).

Based on research on Self-Discrepancy Theory (Higgins, 1999), discrepancies between the actual and the ideal self are causally related to different negative emotions (i.e. dejection/depression) and self-regulatory behaviour, in contrast to discrepancies between the actual and the ought self (i.e. agitation/anxiety). Research on the consequences of actual-feared congruencies, being close to your feared self, is limited but seems to interact with the ought self in causing agitation (Carver et al., 1999). Previous studies confirmed that (the magnitude of) self-discrepancies in chronic pain patients relate to mood disorders such as depression (Morley et al., 2005). In addition, the present study showed that the content of the self-discrepancies does not relate to depression. This finding underpins the Self-discrepancy Theory, stating that the mood disorders are a consequence of the perceived distance between the actual self and the self-guides. From this point of view, it is not surprising that the content in itself was not related to depression. Yet, to regulate their negative moods, patients have to find a way to bring their actual self closer to their self-guides (or further away in case of the feared self) or should adapt their self-guides to more realistic standards.
Furthermore, the content was not related to patients' emotional status but, in line with the hypothesis, it was related to their functional status. Apparently, patients with higher levels of disability generated more well-being related attributes in their ought self In other words, they felt they ought to be for example healthy. It would be interesting to unravel the nature of this relationship. It might be that highly disabled patients mention a higher number of well-being attributes because of the greater discrepancy but it might also be that patients, who compare themselves to more well-being self-guides, feel more disabled.

How do self-guides relate to pain problems? So far, it is not clear how these self-discrepancies might operate in patients with chronic pain and how they possibly influence pain-related behaviours. Sutherland and Morley (2008) also pointed out the importance of future studies to not only focus on self-guides and attributes but to also focus on the self-regulatory behaviours. From a clinical perspective, self system therapy is an example of an intervention which is focused on identifying patients' goals and discrepancies and creating a plan for what patients can do to attain these goals (Strauman et al., 2006; Vieth et al., 2003). In this context, however, knowledge of the content of the self-guides might be useful.

The findings of the present study might also be related to the context of the research setting. That is, as patients underwent the self-discrepancies interview in the context of being engaged in a chronic pain research, the setting could have played a role in that patients might have felt they needed to mention attributes related to their pain. Also, the research setting might also have directed their attention to their pain, making pain-related constructs more accessible. With regard to the methods used in the present study, some limitations have to be taken into account. Although a reduction of categories yielded eight categories that seem to cover meaningful categories in which attributes can be categorized, the original "Physical health" category was merged in a more general cluster of well-being related attributes. Therefore, the selves could no longer be compared on the single "Physical health" category. Possibly, stronger relationships with the level of disability would have been found if this category involved only the physical health status because of the focus on physical well-being instead of general well-being. Related to this, it remains to be determined whether the reduction of categories can be replicated in another population. This research is warranted to further guarantee the reliability and validity of the HSQ categories. Furthermore, the nature of the relation between disability and the content of the selves cannot be termed in causal directions because of a cross-sectional design. Because of these limitations and the fact that the correlation coefficients in the present study were relatively low, cross-validation of the findings is warranted.

In spite of these limitations, this is the first study to look at the content of self-guides in chronic low back pain patients and has shown that the content is related to disability and more specifically to the number of well-being related attributes patients generate. Furthermore, the results draw attention to the fact that next to patient's health status, their interpersonal roles are of great importance and should not be neglected in research or treatment.

\section{Acknowledgements}

The contribution of Hanne Kindermans, Marielle Goossens, Ivan Huijnen and Jeanine Verbunt was supported by ZonMW, Program Rehabilitation Research, Grant No. 60-60500-98015. Participation of Dr. J. Roelofs was supported by the EFIC Grünenthal Grant (EGG). The contribution of Johan W.S. Vlaeyen was supported by the NWO Social Sciences Research Council of The Netherlands, Innovational Grant No. 453-04-003. 


\section{References}

Beck AT, Steer RA, Brown GK. Manual for the Beck depression inventory. 2nd ed. San Antonio (TX): The Psychological Corporation; 1996.

Brouwer S, Kuijer W, Dijkstra PU, Goeken LN, Groothoff JW, Geertzen JH. Reliability and stability of the Roland Morris disability questionnaire: intra class correlation and limits of agreement. Disabil Rehabil 2004;26:162-5.

Carver CS, Lawrence JW, Scheier MF. Self-discrepancies and affect: incorporating the role of feared selves. Pers Soc Psychol Bull 1999;25:783-92.

Chulef SA, Read JS, Walsh AD. A hierarchical taxonomy of human goals. Motiv Emotion 2001;25:191.

Ferrier SS, Brewin CR. Feared identity and obsessive-compulsive disorder. Behav Res Ther 2005;43:1363-74.

Hardin EE, Leong TF. Optimism and pessimism as mediators of the relations between self-discrepancies and distress among Asian and European Americans. J Couns Psychol 2005;52:25.

Harris S, Morley S, Barton SB. Role loss and emotional adjustment in chronic pain. Pain 2003;105:363-70.

Higgins E. Self-discrepancy: a theory relating self and affect. Psychiat Rev 1987:94:319-40.

Higgins E. When do self-discrepancies have specific relations to emotions? The second-generation question of Tangney, Niedenthal, Covert, and Barlow (1998). J Pers Soc Psychol 1999;77:1313-7.

Morley S, Davies C, Barton S. Possible selves in chronic pain: self-pain enmeshment, adjustment and acceptance. Pain 2005;115:84-94.

Morley S, Eccleston C. The object of fear in pain. In: Asmundson GJ, Vlaeyen JW, Crombez G, editors. Understanding and treating fear of pain; 2004.
Price DD, McGrath PA, Rafii A, Buckingham B. The validation of visual analogue scales as ratio scale measures for chronic and experimental pain. Pain 1983;17:45-56.

Ranjan R. Chronic pain, loss, and suffering. Toronto: University of Toronto Press;

Roland M, Morris R. A study of the natural history of back pain. Part I: development of a reliable and sensitive measure of disability in low-back pain. Spine 1983;8:141-4.

Smith JA, Osborn M. Pain as an assault on the self: an interpretative phenomenological analysis of the psychological impact of chronic benign low back pain. Psychol Health 2007;22:517-34.

Strauman TJ, Vieth AZ, Merrill KA, Kolden GG, Woods TE, Klein MH, et al. Selfsystem therapy as an intervention for self-regulatory dysfunction in depression: a randomized comparison with cognitive therapy. J Consult Clin Psychol 2006;74:367-76.

Sutherland R, Morley S. Self-pain enmeshment: future possible selves, sociotropy, autonomy and adjustment to chronic pain. Pain 2008;137:366-77.

Van Damme S, Crombez G, Eccleston C. Coping with pain: a motivational perspective. Pain 2008;139:1-4.

Vieth A-Z, Strauman T-J, Kolden G-G, Woods T-E, Michels J-L, Klein M-H. Selfsystem therapy (SST): a theory-based psychotherapy for depression. Clin Psychol Sci Pract 2003;10:245-68.

Waters SJ, Keefe FJ, Strauman TJ. Self-discrepancy in chronic low back pain: relation to pain, depression, and psychological distress. J Pain Symptom Manag 2004;27:251-9. 